\title{
Assessment of the professional competencies formation in students in the course of implementing online digital learning technologies
}

\author{
Svetlana G. Zakharova ${ }^{1 *}$, Sergey N. Yashin ${ }^{1}$, Lyudmila F. Sukhodoeva ${ }^{1}$, Natalia S. \\ Somenkova ${ }^{1}$, and Sergey $V$. Tumanov ${ }^{2}$ \\ ${ }^{1}$ Lobachevsky State University of Nizhny Novgorod - National Research University, Institute of \\ Economics and Entrepreneurship, Department of Management and Public Administration, Nizhny \\ Novgorod, Russia \\ ${ }^{2}$ Nizhny Novgorod State Agricultural Academy, Department of Educational and Methodical \\ Management, Nizhny Novgorod, Russia
}

\begin{abstract}
The article substantiates the relevance of research on the assessment of students' professional competencies in the course of implementing online digital learning technologies at universities, as well as unpacks the features of the flipped learning system as a means of determining the assimilation of competencies by students in the studied disciplines. The authors consider the flipped learning implementation methods, such as information collection, analysis, systematization, understanding, application, and competencies. It is shown that digital technologies in education, being a complicated multifunctional complex of influence on the quality of education, have a very ambiguous effect on the formation of professional competencies. Revealed specifics of using highquality resources when creating digital technologies include special illustrations, a large number of diagrams, animations, audio fragments, web3.0, video fragments, interactive tasks, animated presentation forms, maps, analytical tables, digital content designed according to the rules of digital communications, its presence in social networks, and much more. The sociological study was conducted involving groups of intramural students of one of the leading universities of the Russian Federation. The professional competencies that students receive in the context of the implementation of online technologies have been assessed. The results of sociological study on students' readiness for flipped learning have been presented in graphical form. The authors have analyzed the effectiveness of different forms of classes, such as lectures, practical classes, and control, as well as have systematized the trends of educational processes digitalization, and their role in the development of economic processes.

Keywords: digitalization of education, innovative educational technologies, professional competencies, flipped learning, digitalization control, storytelling.
\end{abstract}

\footnotetext{
*Corresponding author: svetlana-nngu@mail.ru
} 


\section{Introduction}

The relevance of research on the assessment of students' professional competencies in the course of implementing online digital learning technologies is obvious. Continuously changing digital technologies make it necessary to constantly improve skills, and develop digital skills to remain in demand in the profession, to be able to get an interesting job in contemporary organizations that are reoriented to digital technologies [1]. To assess the use of digital technologies in education, the authors conducted a study among intramural students to reveal the level of acquired competencies in the context of an urgent transition to online learning.

The education system needs to increase students' confidence in the possibility of implementing their abilities in the field of information technology [2]. In the context of new standards of distance learning, meaningful content presented in innovative forms is more important than ever. Moreover, the valuation resources should correspond to contemporary digital learning technologies and making decisions in practical situations for students to develop their scientific worldview and its effective application in their professional activities.

\section{Methods. The flipped learning system}

In the context of the rapid digitalization of learning, special attention should be paid to the flipped learning system. In the online format, as in the traditional ones, it includes three types of work with students:

- the lecture content provides for an independent understanding of the material of the provided content, followed by analysis and systematization of information;

- practical classes aimed at training knowledge and skills in certain competencies, regardless of the digital platform on which the training takes place;

- knowledge control is based on the organization of interaction and feedback, which allows the teacher and students to become partners in the learning process and complement the material being mastered with innovative ideas.

The culture of flipped learning uses the Pareto principle, when $20 \%$ of the learning material is absorbed by the student independently, while $80 \%$ of material student masters through discussions and discourses in the classroom. The training goal is activating the work of students through practicing various critical thinking techniques, elements of collaboration, film-making, personification, and using social networks rather than just providing certain content. The student gets the skills of virtual thinking, and his activity serves as an indicator in the assessment of acquired competencies. Flipped learning is a more active form compared to traditional teaching methods since the collaboration system turns the process of joint activities for teaching students into a partnership, in which knowledge is shared, as well as learning and consensus are reached on controversial issues [3]. In contrast to B. Bloom's taxonomy of cognitive skills, presented in the upper part of Figure 1, in the case of flipped learning, the pyramid is flipped [4] and takes the form shown in the lower part of Figure 1. 


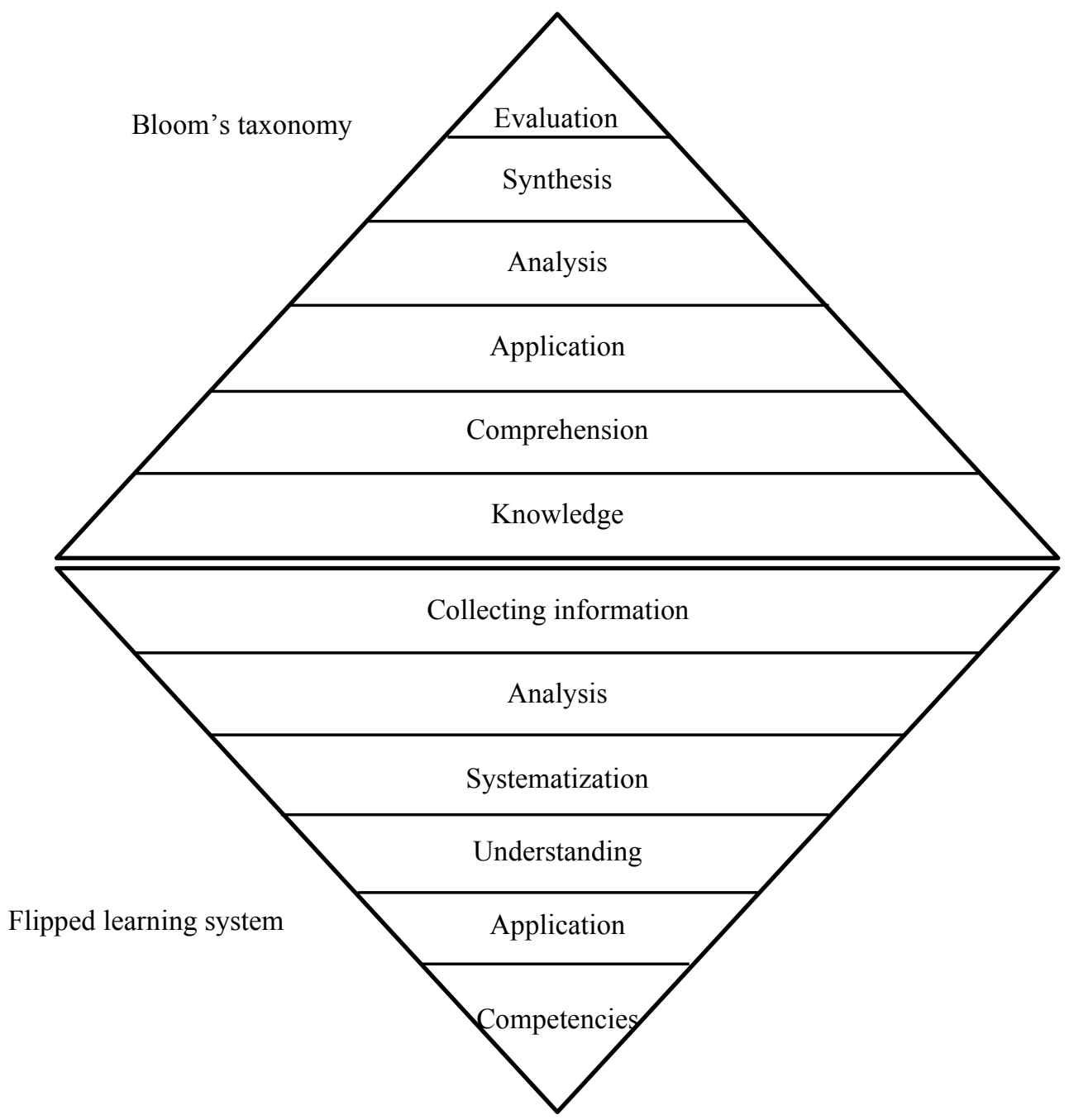

Fig. 1. The pyramid of flipped learning.

Tasks for extracurricular work can include both individual methods of mastering scientific knowledge, and integrated approaches to making decisions on practical tasks. The research activity is the most difficult type of practical work [5]. The most effective tool is storytelling, as the interactive art of giving certain form and meaning to boring information to encourage the listener's imagination. This allows not only conducting research in professional activities but also using contemporary methods and means of research, search, analysis, and systematization of scientific digital information, thereby ensuring sociallyoriented human resource management [6]. 


\section{Results}

\subsection{Assessment of professional competencies received by students in the course of online learning}

Studying the results of the assessment by students of the received competencies, defined in the standard in the context of the implementation of online technologies, has shown many interesting aspects (Fig. 2).

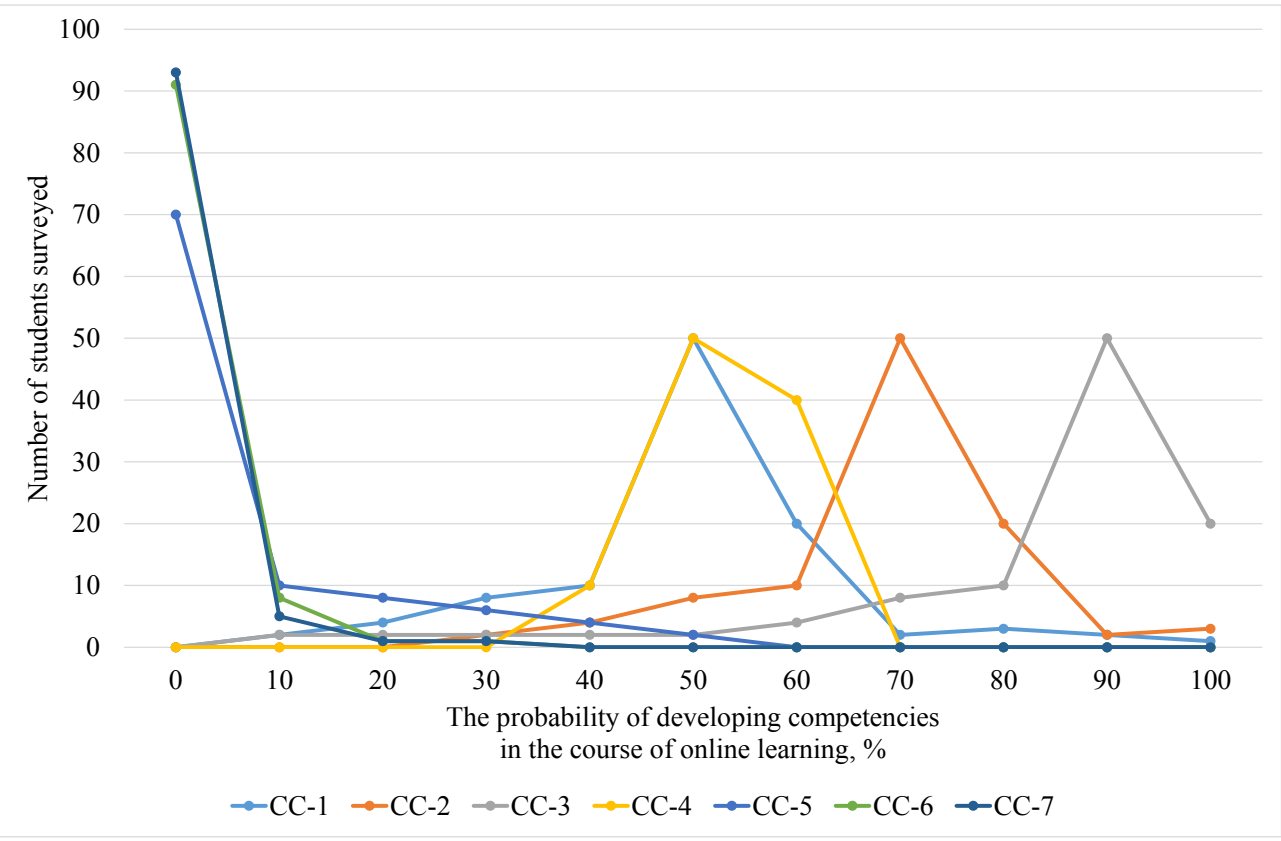

Fig. 2. Analysis of common cultural competencies (CC) formed in the course of online learning.

CC-1 - the ability to use the basics of philosophical knowledge to form a worldview position; CC-2 the ability to analyze the main stages and patterns of the historical development of society for the formation of civic position; $\mathrm{CC}-3$ - the ability to use the basics of economic knowledge in various fields of activity; CC-4 - readiness for communication in oral and written forms in Russian and foreign languages for solving problems of professional activity; CC-5 - the ability to work in a team, tolerantly perceiving social, ethnic, confessional and cultural differences; CC- 6 - the ability to use methods and means of physical culture to ensure full-fledged social and professional activity; CC-7 - the ability to use first aid techniques, methods of protection in emergency situations.

Figure 2 shows that the rapid transition of the education system to online learning is not fully ready to ensure forming a complete list of competencies. The implementation of the flipped learning system into the practice of educational processes is quite capable of changing the situation.

\subsection{Readiness of students for flipped learning}

The assessment of receiving competencies in different formats of classes is presented in the form of pie charts in Fig. 3. 
a) Lectures

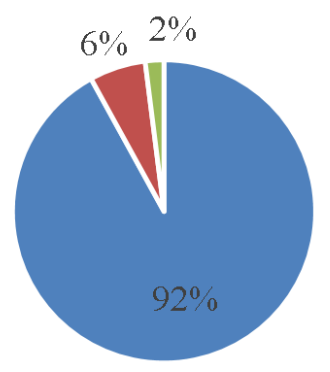

b) Practical and laboratory classes

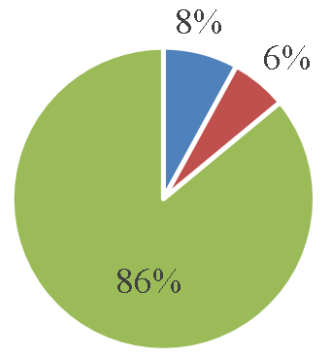

c) Control

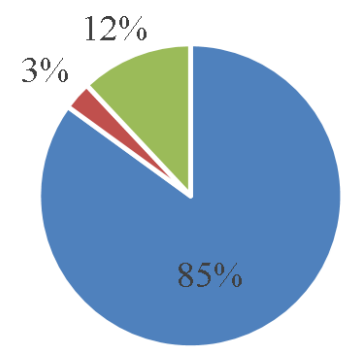

The most convenient format for competencies formation online

The format doesn't important

The least convenient format for the competencies formation in person

Fig. 3. Assessment of the usability of digital technologies in training.

At that, each competency is interpreted as an integral characteristic of the student, a dynamic digital set of his knowledge, skills, abilities, and personal qualities, which the student must demonstrate after completing the entire educational program. It should be noted that there are serious differences between the concepts of educational outcomes and acquired competencies. The educational outcomes are determined by the teacher, while competencies are acquired by students who provide a competitive labor market [7]. The labor market is characterized by intense competition for factors of production, human potential, and investments, while at the same time, it demonstrates a lack of interaction culture among the subjects of socio-economic relations since important professional competencies have not been developed [8].

The role of instructional content in flipped learning is to design individual educational trajectories as the main goal of learning [9].

In the context of digitalization, it is important to form, maintain and develop the skills in university graduates relevant to Industry 4.0. [10]. Updating and accumulating students' knowledge using digital technologies should meet the increased requirements of employers [11]. In the system of education-science-production, digital competencies become a key factor that, being transformed into an intellectual resource, generates effective development of the system [12].

\section{Conclusion}

The development of online education is becoming mandatory in the contemporary world and increasingly affects the formation of the individual, culture, and society [13].

According to scientists, an interactive learning model, based on the predominant use of distance technologies, will become the dominant form of acquiring new knowledge [14]. New digital competencies can be formed only by taking into account the modeling of digital nourishing technologies, in which knowledge is adapted in a professional environment. The national system of forming a comfortable investment and innovation climate, as well as a 
developed institutional environment become of particular importance as a condition that brings the system of forming students' competencies as close as possible to their future professional practice $[15,16]$.

\section{References}

1. O sisteme realizacii programmy "Cifrovaya ekonomika Rossijskoj Federacii". [About the implementation of the program "Digital Economy of the Russian Federation"]. Resolution of the Government of the Russian Federation of 28.08.2017, No. 1030. Accessed on: December 10, 2020. [Online]. Available: http://government.ru/docs/29003/

2. E.K. Khenner, C. Frieze, O. Zane, The Education and Science Journal, 22(8), 189-206 (2020). https://doi.org/10.17853/1994-5639-2020-8-189-206.

3. T.V. Stozharova, N.D. Sukhodoev, Innovacionnye metody obucheniya na osnove situacionnogo podhoda [Innovative teaching methods based on the situational approach], in Proceedings of the Methodological Conference of the Lobachevsky State University of Nizhny Novgorod "Innovative Methods of Teaching at the University", The Lobachevsky State University of Nizhny Novgorod, Nizhny Novgorod, Russia, 119-121 (2015)

4. A.A. Ivanov, S.N. Yashin, N.D. Ivanova, Analiz sovremennogo sostoyaniya $i$ formirovaniya cifrovoj ekonomiki Rossii [Analysis of the current status and formation of the digital economy of Russia], in Proceedings of the Scientific and Practical Conference with Foreign Participation "Digital Transformation of the Economy and Industry”, St. Petersburg, Russia,104-113 (2019)

5. L.F. Sukhodoeva, J. Coe, Bulletin of the Lobachevsky State University of Nizhny Novgorod, 2-1, 278-282 (2014)

6. S.G. Zakharova, Bulletin of the Lobachevsky State University of Nizhny Novgorod, 3, 7-16 (2016)

7. D.V. Sukhodoev, N.D. Sukhodoev, Innovacionnoe razvitie regiona na osnove ego resursnogo potenciala [Innovative development of the region based on its resource potential], in Proceedings of the International Scientific and Practical Conference "Urgent Problems of Contemporary Science", 241-245 (Omega Science, Ufa, 2013)

8. S.G. Zakharova, N.S. Somenkova, Economic Research and Development, 4, 164-167 (2019)

9. T.O. Krasnopeeva, A.I. Shevchenko, S.K. Gural, Language and Culture, 51, 153-176 (2020). https://doi.org/10.17223/19996195/51/8

10. D.S. Konstantinova, M.M. Kudaeva, Labor Economics, 7(11), 1055-1072, (2020). https://doi.org/10.18334/et.7.11.111073

11. N.S. Somenkova, Bulletin of the Saratov State Socio-Economic University, 3(22), 93 95 (2008)

12. M.M. Batova, Issues of Innovative Economy, 9(4), 1573-1584 (2019). https://doi.org/10.18334/vinec.9.4.41467

13. H.S. Zaghloul, D.S. Mahdy, The Education and Science Journal, 22(8), 41-74 (2020). https://doi.org/10.17853/1994-5639-2020-8-40-74

14. E.O. Chernykh, Economy, Entrepreneurship, and Law, 10(11), 2827-2848 (2020). https://doi.org/10.18334/epp.10.11.111127.

15. S.G. Zakharova, International Journal of Professional Science, 1, 33-40 (2017) 
16. V.N. Yasenev, L.F. Sukhodoeva, Bulletin of the Lobachevsky State University of Nizhny Novgorod. Series: Innovations in Education, 1, 153-154 (2003) 